\title{
Double Functioning Free Muscle Transfer as a Salvage Procedure for Brachial Plexus Injury After Failed Nerve Transfer
}

\author{
Jerry Tsung-Kai Lin, MD; Johnny Chuieng-Yi Lu, MD*; \\ Tommy Nai-Jen Chang, MD; David Chwei-Chin Chuang, MD
}

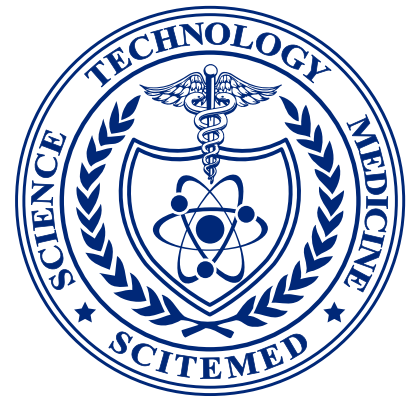

Division of Reconstructive Microsurgery, Department of Plastic Surgery, Chang Gung Memorial Hospital, Linkou Branch, Taoyuan, Taiwan

A 29-year-old male suffered from total loss of function of his left shoulder and upper limb after a traffic accident while riding a motorcycle. He was treated by a brachial plexus specialist at another hospital and managed surgically under the impression of total root avulsion.

He was treated initially with distal nerve transfer, using spinal accessory nerve to suprascapular nerve for shoulder abduction, and intercostal nerves T3, T4, and T5 to musculocutaneous nerve for elbow flexion. Four months later, he received contralateral C7 transfer to median nerve with a vascularized ulnar nerve graft for hand flexion and sensation. However, there was no recovery of elbow or finger contraction two years after the initial operation. He then received functioning free muscle transplantation as a salvage procedure using gracilis muscle for elbow flexion, with the reuse of T3 and T4 intercostal nerves as neurotizers. The ipsilateral neck and the supraclavicular brachial plexus were never explored in any of these surgeries.

Unfortunately, the free functioning muscle transfer (FFMT) was unsuccessful and the muscle power of the gracilis remained at M1 status without any progression. He then came to our unit for help. The patient showed weak elbow flexion, with no finger flexion, but some recovery of median nerve sensation. Due to the lack of extraplexus donors, we arranged MRI of the left neck to search for viable roots, and surprisingly it showed ruptured $\mathrm{C} 5$ and $\mathrm{C} 6$ roots without avulsion. Thus, we planned for a two-staged surgery. At the first stage, we identified viable stumps of $\mathrm{C} 5$ and $\mathrm{C} 6$ roots. We harvested two sural nerve grafts as extension cables of the $\mathrm{C} 5$ and $\mathrm{C} 6$ roots, and passed the distal ends under clavicle, pectoralis minor and major muscles to be buried in the dermis of the left axilla region. The second stage of surgery was done 11 months later after the tinel signs reached the axillary destination. Tensor fascia lata was first harvested and attached to the clavicle for muscle elongation. Both gracilis and adductor longus muscle were harvested with common pedi-

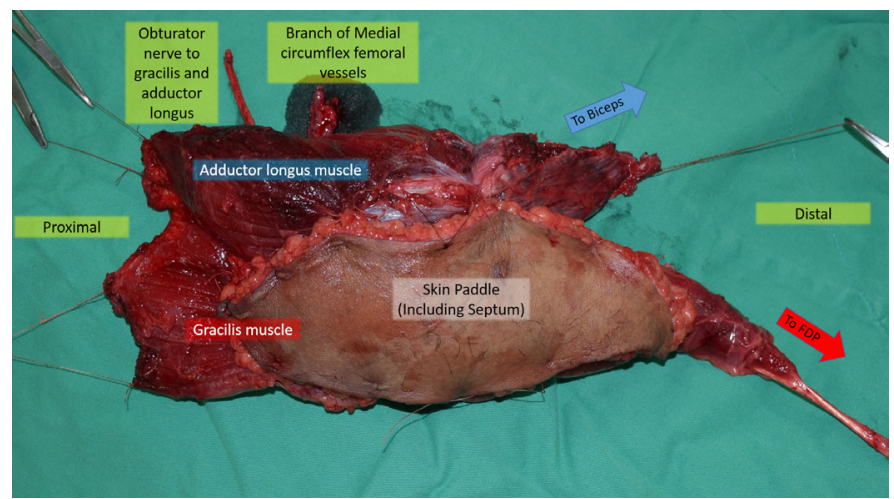

Figure 1. A scheme of the harvested double functional free muscle. The two muscles are based on a common vascular pedicle, but with two different innervating nerves. cle vessels, but with two different innervating nerves, and their proximal ends were sutured to the elongated tensor fascia lata (Figure 1). The distal end of gracilis tendon was sutured to the tendon of flexor digitorum profundus in an end-to-end fashion, while that of adductor longus was sutured to distal biceps tendon under appropriate tension (Figure 2). The anterior circumflex humeral arteries and basilar veins were anastomosed to the common pedicle of the two functioning free muscles (Figure 3).

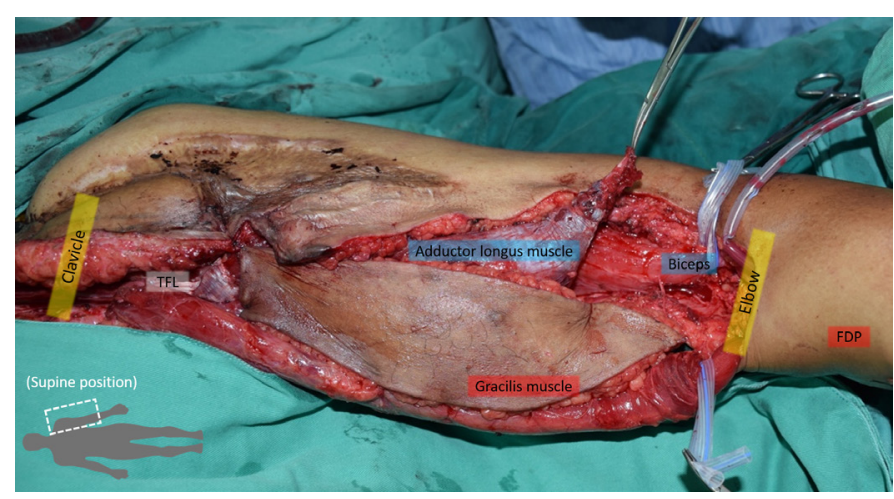

Figure 2. The proximal end of the FFMT was attached to the tensor fascia lata, while the distal end of the gracilis and adductor longus were attached to the flexor digitorum profundus and the distal biceps respectively. FFMT, free functioning muscle transfer.

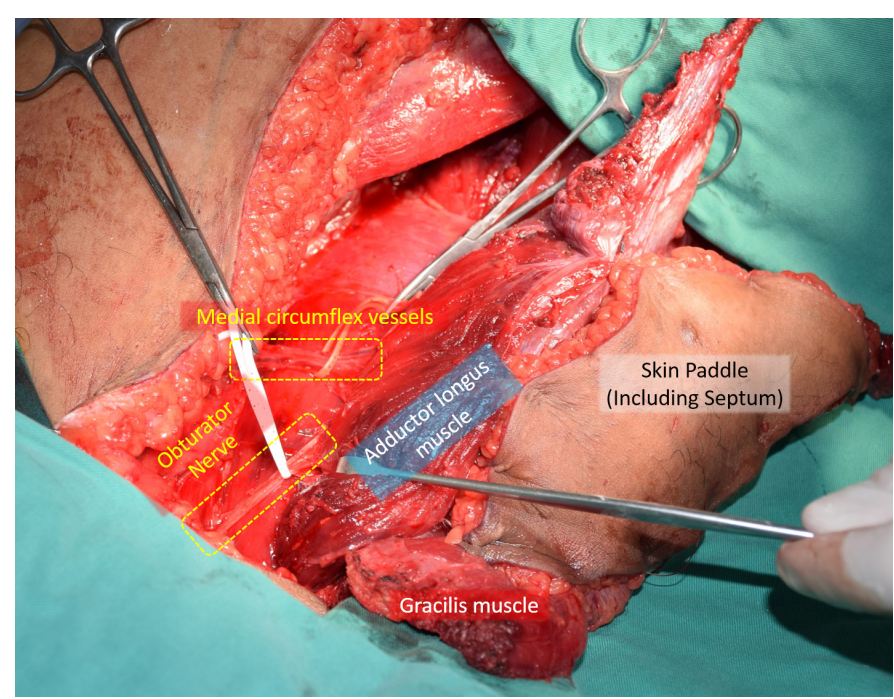

Figure 3. The anterior circumflex humeral arteries and basilar veins were anastomosed to the common pedicle of the two functioning free muscles. 


\section{IMAGE}

The extension sural nerve grafts were coapted separately to the innervating nerves of the adductor and gracilis muscles. The schemes regarding the cooptation of the nerves and the divisions of the obturator nerve are shown respectively in Figure 4 and Figure 5.

We harvested the gracilis and adductor longus muscles because one gracilis muscle was already wasted in the previous failed FFMT. The two functioning free muscles are based on one common pedicle from the other thigh. Less surgical time and less anastomosis can be achieved based on this double muscle technique. The patient is under rehabilitation at present, muscle power regained to $\mathrm{M} 2$ status 7 months after surgery, with visible contractions in the proximal muscles, but unable to show any significant movement.

\section{Article Information}

*Correspondence: Johnny Chuieng-Yi Lu, MD

Division of Reconstructive Microsurgery, Department of Plastic Surgery, Chang Gung Memorial Hospital, Linkou Branch, Taoyuan City, Taiwan. E-mail: cylu122@gmail.com

Received: Jun. 25, 2017; Accepted: Oct. 05, 2017; Published: Dec. 09, 2017

DOI: 10.24983/scitemed.imj.2017.00046

Copyright (c) 2017 The Author(s). This is an open-access article distributed under the terms of the Creative Commons Attribution 4.0 International License (CC-BY).

Funding: None

Conflict of Interest Disclosures: None

\section{Stage 1}

$\begin{array}{ll}\text { C5 stump } & \text { Sural nerve graft I } \\ \text { C6 stump } & \text { Sural nerve graft II }\end{array}$

\section{Stage 2}

Nerve to adductor longus

Nerve to gracilis

Figure 4. The scheme regarding the coaptation of the nerves. The sural nerve grafts were used as extension cables of the C5 and C6 roots, and were coapted separately to the innervating nerves of the adductor and gracilis muscles.

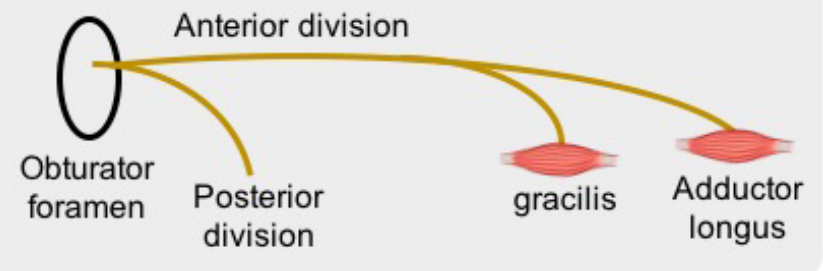

Figure 5. The divisions of the obturator nerve. The branch innervating the adductor longus and the gracilis muscles both account for the anterior division of the obturator nerve. 